\title{
Mycoplasma moatsii, a New Species Isolated from Recently Imported Grivit Monkeys (Cercopithecus aethiops)
}

\author{
DAVID L. MADDEN, KENNETH E. MOATS, WILLIAM T. LONDON, \\ EARL B. MATTHEW, ${ }^{\prime}$ and JOHN L. SEVER
}

National Institute of Neurological Diseases and Stroke, Bethesda, Maryland 20014

\begin{abstract}
Six Mycoplasma isolates, comprising a new species of Mycoplasma, were isolated from grivit monkeys recently imported from Ethiopia. These isolates metabolized both arginine and glucose but not urea. Growth occurred anaerobically and aerobically in media containing $20 \%$ horse serum or $1 \%$ serum fraction but not in media without serum. By metabolic-inhibition and indirect immunofluorescent techniques, these strains were shown to be serologically related to each other but unrelated to 9 other species from man and monkeys as well as to HRC/292 simian isolates and 26 species isolated from other animals. By immunodiffusion techniques, major sharing of antigenic determinants with the human Mycoplasma strains was not observed. Although the host-parasite relationship of these isolates has not been determined, at the time of isolation they were not associated with disease in the grivit monkey. On the basis of these findings, we propose that these new isolates be recognized as constituting a new species, for which we propose the name Mycoplasma moatsii. The type strain is MK 405 (=ATCC 27625).
\end{abstract}

In a previous study, we reported that the predominant species of Mycoplasma recovered from recently imported grivit monkeys ( $\mathrm{Cer}$ copithecus aethiops) were $M$. orale II (sic), $M$. salivarium, and $M$. primatum (5). It was also found that 6 isolates were similar to each other but serologically different from the 19 species previously isolated from man or other animals. The serological and biological characteristics of these isolates suggest that they constitute a new species.

\section{MATERIALS AND METHODS}

Mycoplasma serotypes. The strains of the standard species of human, animal, and avian mycoplasmas used in this study are listed in Table 1. Three additional strains $(291,292$, and M35) were obtained from M. Barile, and one strain (B291) was obtained from $J$. Tully. These latter four strains were isolated from monkeys.

The Mycoplasma isolates described in this report were obtained from recently imported grivit monkeys as previously described (5). Five of the strains were isolated from the reproductive tract, two from males and three from females. One isolate was recovered from the throat, and a similar one was isolated from the reproductive tract of the same animal.

Media. The medium used for the isolation of

${ }^{1}$ Present address: Section on Infectious Diseases, University of Texas Medical School at San Antonio, San Antonio, Tex. 78240. mycoplasmas was similar to the medium of Chanock et al. $(2,4)$. It consisted of Difco PPLO broth which contained $10 \%$ of a $25 \%$ fresh yeast extract and $20 \%$ sterile horse serum. In addition, the bacterial inhibitors thallium acetate $(1: 2000$, final dilution) and penicillin $(1000 \mathrm{U} / \mathrm{ml})$ were added (HS broth). Agar plates were prepared by substituting Difco PPLO agar for the broth (horse serum [HS] agar). As soon as possible after isolation, all strains were adapted to grow in Difco PPLO broth which contained $10 \%$ of a $25 \%$ fresh yeast extract, $1 \%$ Difco PPLO serum fraction, and the above bacterial inhibitors (serum fraction [SF] broth).

Cloning of Mycoplasma strains. Mycoplasma isolates were cloned by selecting individual colonies from HS agar. Cultures from the third cloning were used for antigen preparations.

rruduction of hyperimmune rabbit serum. Antigens were prepared in $\mathrm{SF}$ broth. The clones were passed in SF broth at 2- to 3-day intervals. The final volume of broth contained a $10 \%$ inoculum and was incubated 2 or 3 days before harvesting. The antigen was concentrated in a refrigerated centrifuge at $12,000 \times g$ for 1 $h$. The pellet was suspended and washed three times in phosphate-buffered saline ( $\mathrm{pH}$ 7.5). After the last wash, the organisms were resuspended in buffered saline (pH 7.5) containing a 1:10,000 dilution of merthiolate to equal $100 \times$ concentration of the original broth culture. Hyperimmune serum was produced in rabbits by intramuscular injection of 1.5 $\mathrm{ml}$ of antigen emulsified in $1.5 \mathrm{ml}$ of Freund complete adjuvant as suggested by Morton (6).

Test for utilization of substrate and requirement for nutrient factors. Mycoplasmas were cultivated for at 
TABLE 1. Strains and sources of organisms used in this study ${ }^{a}$

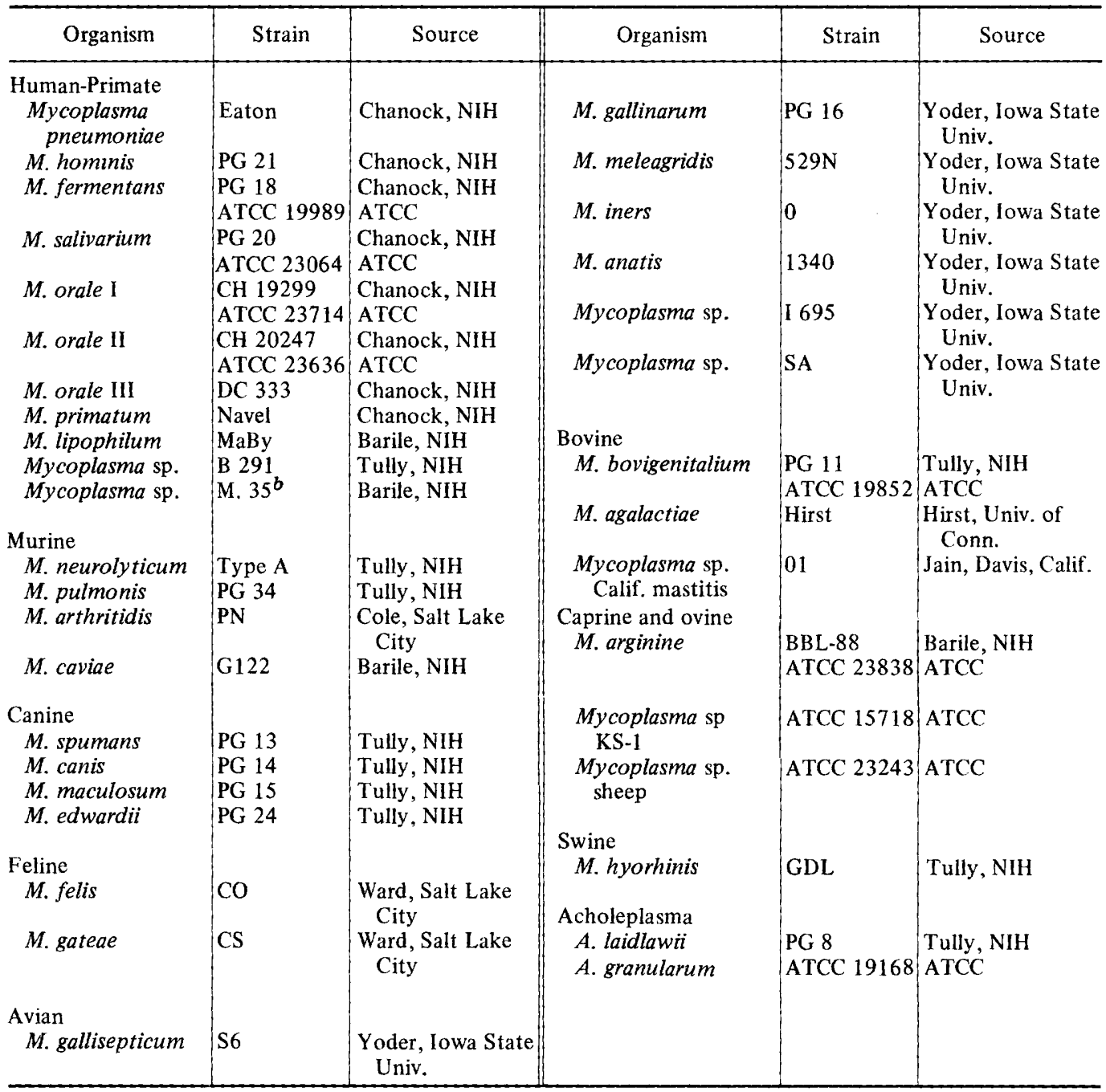

${ }^{a}$ ATCC, American Type Culture Collection; NIH, National Institute of Health.

${ }^{b}$ One-way cross.

least three passages in SF broth (thallium acetate was not added to SF broth to be used for urea-utilization determinations) which contained $0.002 \%$ phenol red and one of the following additives: $1 \%$ glucose, $1 \%$ arginine, $0.1 \%$ urea, or $1 \%$ urea. The glucose medium was adjusted to pH 7.8 with $1 \mathrm{~N} \mathrm{NaOH}$, and the arginine medium was adjusted to $\mathrm{pH} 7.0$ with $1 \mathrm{~N} \mathrm{HCl}$. The urea medium which did not contain thallium acetate was adjusted to $\mathrm{pH} 6.5$ with $1 \mathrm{~N} \mathrm{HCl}$. A change in $\mathrm{pH}$ of 0.5 units in three subsequent subpassages was considered evidence for utilization of the substrate. The oxidative utilization of glucose was determined by sealing the inoculated tubes with a Vaseline-paraffin mixture and examining for color change during a period of 2 weeks (1). Controls for utilization of the substrates consisted of SF broth (without thallium acetate for urea utilization) contain- ing phenol red (adjusted to the desired $\mathrm{pH}$ ) and the mycoplasmas. Decolorization of methylene blue was determined by inoculating $0.1 \mathrm{ml}$ of a $0.1 \%$ methylene blue solution into $3 \mathrm{ml}$ of a 24 -h broth culture; one tube was incubated aerobically, and the other was sealed with the Vaseline-paraffin mixture (1). Tetrazolium reduction was determined by inoculating $H S$ agar plates containing $0.2 \%$ of 2,3,5-triphenyltetrazolium chloride; one set was incubated aerobically, and the other set was incubated in an atmosphere of $95 \% \mathrm{~N}-5 \% \mathrm{CO}_{2}$ (1). In addition, the isolates were cultivated in medium devoid of horse serum and serum fraction to determine ability to grow in medium free of serum. All cultures were subcultured onto HS agar to check for viability.

Serological tests. Metabolic-inhibition (MI) tests were performed on the cultures using reciprocal 
antigen-antibody combinations. The techniques were a modification of the microtiter technique used by Purcell et al. $(7,8)$. The tests were performed with $0.025-\mathrm{ml}$ droppers and spiral loops in disposable Microtests II plates. Two 10-fold dilutions (of a 24-h broth culture) containing 10 or 100 organisms were used as the antigen. The plates were read at 2, 5, 7, and 10 days with a mirror directly under a fluorescent light. Controls consisted of 10 -fold serial dilutions of the whole broth culture to determine the exact number of organisms in the antigen dilutions and antigen dilutions without hyperimmune antisera. The titer of the culture was considered to be the last dilution in which a $\mathrm{pH}$ change of at least $0.5 \mathrm{log}$ occurred. The titer of the serum was considered to be the last dilution of serum which inhibited a $\mathrm{pH}$ change of more than $0.5 \mathrm{log}$.

Indirect fluorescent-antibody tests were performed on reciprocal antigen-antibody combinations. The killed antigens were attached to glass slides by incubation at $37 \mathrm{C}$ for $10 \mathrm{~min}$. Twofold dilutions of antisera were added to the slides, and the slides were incubated in a moist chamber at room temperature for $30 \mathrm{~min}$, rinsed with saline, and dried at $37 \mathrm{C}$. An appropriate dilution of fluroescence-tagged anti-rabbit globulin was added, and the slides were incubated as before, rinsed in saline and then distilled water, and dried. A cover slip was placed over the slide, which was then examined by fluorescent microscopy.

Agar-gel diffusion tests were performed with the $100 \times$ concentrations of mycoplasma in agar-gel diffusion plates. The antigen was frozen and thawed three times before being used and was stored thereafter at $4 \mathrm{C}$.

Electron microscopy. A 24-h broth culture grown in SF broth was concentrated $100 \mathrm{X}$ in a refrigerated centrifuge at $10,000 \times g$ for $15 \mathrm{~min}$. The pellet was fixed overnight in $2 \%$ gluteraldehyde in cacodylate buffer ( $\mathrm{pH}$ 7.3). The pellet was then cut into small fragments and rinsed several times in cacodylate buffer before post-fixing in Dalton chrome-osmium. Dehydration was accomplished by passing the sample through a graded series of methyl alcohol and into propyline oxide before embedding in Epon-Araldite. Thin sections were prepared on an LKB ultratome 3600 using glass knives. The sections were mounted on uncoated copper grids and stained with uranyl acetate and lead citrate. The sections were examined and micrographs prepared with an Hitachi HU-1 lE-1 electron microscope.

\section{RESULTS}

Our six new isolates appear to belong to a new species, the biochemical reactions of which are summarized in Table 2. As previously described (5), they were isolated in HS broth under anaerobic conditions. They readily adapted to growth in SF broth in aerobic conditions with titers ranging from $10^{7}$ to $10^{9}$ colony-forming units or color-changing units per $\mathrm{ml}$. The strains produced slight turbidity in SF broth. Typical Mycoplasma colony morphology was observed on agar plates. All strains metabolized glucose and arginine, with the production of a very striking change in the $\mathrm{pH}$ of the medium. None of the strains utilized urea. When horse serum or serum fraction was omitted from the medium, the organisms did not grow in subsequent passages.

The cells of one of the isolates appeared to be essentially spheroidal and to vary in size from approximately 300 to as much as 1,200 $\mathrm{nm}$ (Fig. 1 and 2). The cells were surrounded by a triple-layered membrane, contained particulate material suggestive of ribosomes, and had a variable density, which became greater with decreasing size. In the moderately dense particles of the cells, a layer of dense material was seen just beneath the outer, limiting membranes. There was evidence of budding at the surface of some of the cells (Fig. 2).

The serological relationship of the six strains was established by the indirect fluorescentantibody and the MI tests (5).

Lack of a serological relationship to the known species of Mycoplasma studied (Table 1) was established by the use of the MI and

TABLE 2. Biochemical properties of Mycoplasma and Acholeplasma species isolated from primates

\begin{tabular}{|c|c|c|c|c|c|c|c|}
\hline \multirow[b]{2}{*}{ Organism } & \multicolumn{2}{|c|}{ Glucose fermentation } & \multirow{2}{*}{$\begin{array}{c}\begin{array}{c}\text { Arginine } \\
\text { Metabolism }\end{array} \\
\text { Aerobic }\end{array}$} & \multicolumn{2}{|c|}{$\begin{array}{l}\text { Methylene blue } \\
\text { reduction }\end{array}$} & \multicolumn{2}{|c|}{ Tetrazolium reduction } \\
\hline & Anaerobic & Aerobic & & Anaerobic & Aerobic & Anaerobic & Aerobic \\
\hline Mycoplasma hominis & - & - & + & - & - & - & - \\
\hline$M$. salivarium & - & - & - & - & - & - & - \\
\hline M. fermentans & + & + & + & + & - & - & - \\
\hline M. orale I & - & - & + & - & - & - & - \\
\hline$M$. orale II & - & - & + & - & - & - & - \\
\hline M. primatum & - & - & + & + & - & - & - \\
\hline Acholeplasma laidlawii & + & + & - & + & + & + & + \\
\hline M. moatsii & + & + & + & - & - & - & - \\
\hline
\end{tabular}

${ }^{a}$ Growth was obtained without serum fraction. 


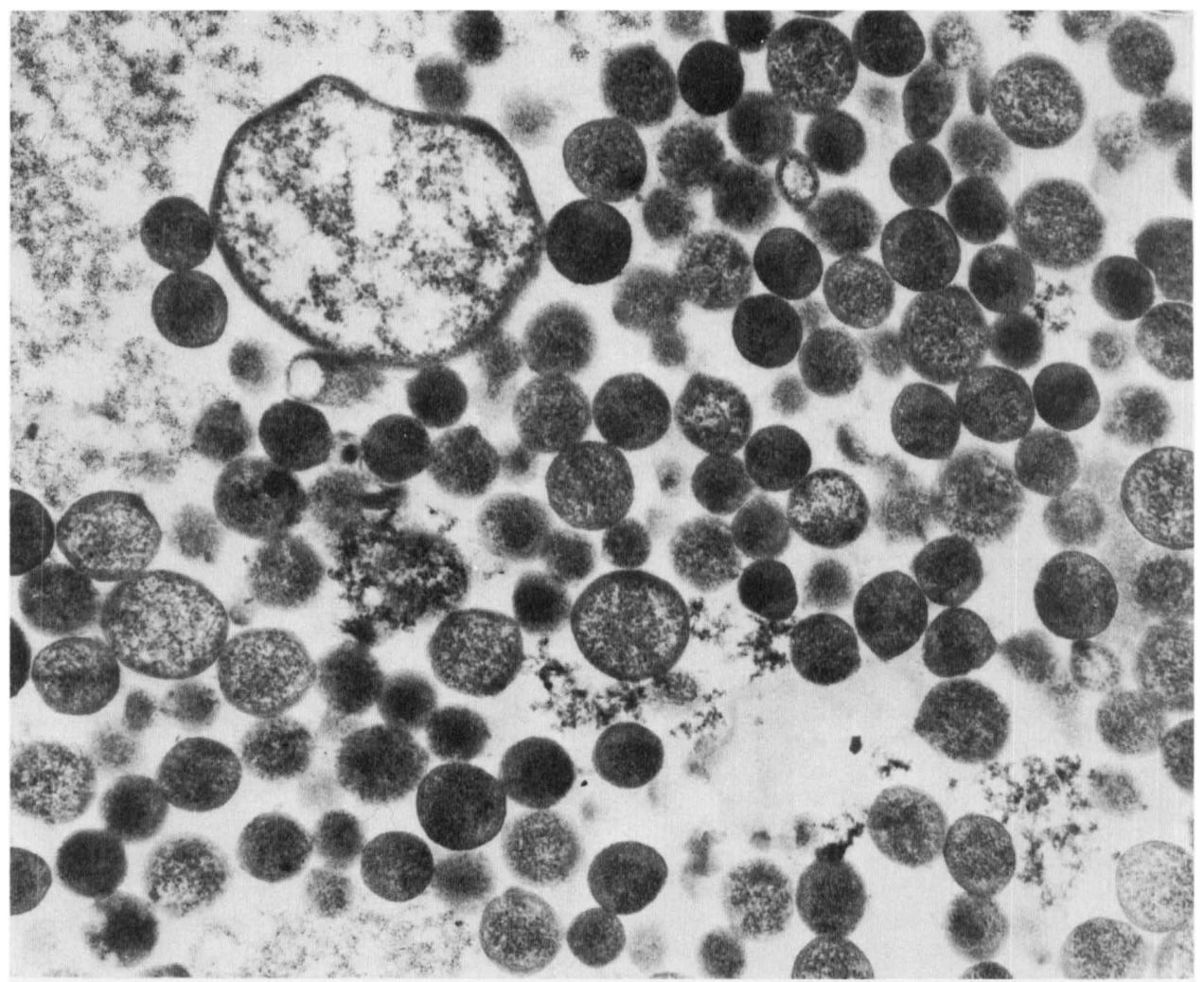

FIG. 1. Electron micrograph of strain MK 405. Final magnification, $\times 32,50 Q$.

indirect fluorescent-antibody tests. In reciprocal crosses between MK 405 and the other serotypes, no MI titers greater than 1:8 or no indirect flourescent-antibody titers greater than 1:10 were observed. The results of the MI tests using serotypes isolated from primates are shown in Table 3. As can be observed, high levels of homologous MI antibodies were produced in rabbits. Two additional strains are reported to utilize both glucose and arginine; M. fermentans (PG 18) will decolorize methylene blue, whereas MK 405 does not. The sheep strain differs from both $M$. fermentans and MK 405 in that it weakly breaks down glucose. The MI test (Table 4) indicates that $M$. fermentans (PG 18), the sheep strain (ATCC 23243), and MK 405 are not serologically related.

Previous studies utilizing the agar-gel precipitation test have revealed serological relationships between many of the serotypes isolated from man (3). We have also observed crossrelationships between many of the human strains. The antigen-antibody reaction between MK 405 and antisera produces three bands: one major band and two smaller ones. Some cross-reactions between the inner small band of the MK 405 serotype and a minor component of a number of other serotypes occurred. Controls with medium or medium treated in a similar manner as the antigen did not yield similar bands.

\section{DISCUSSION}

The data presented here indicate that the isolate MK 405 represents a new serotype, which may be indigenous to monkeys. Serological studies were not performed with three species, $M$. synoviae from chickens and $M$. hyoarthritidis and $M$. hyopneumoniae from swine. However, these three species differ from MK 405 in that they can not be grown in HS broth or SF broth and do not utilize glucose or arginine.

This new serotype of Mycoplasma seems to be present only in grivit monkeys. None of the cultures recovered from tissue cultures, cats, rats, chickens, rhesus monkeys, or man have been related to this species. The monkeys from which this serotype was isolated were recently imported into the United States from Ethiopia 


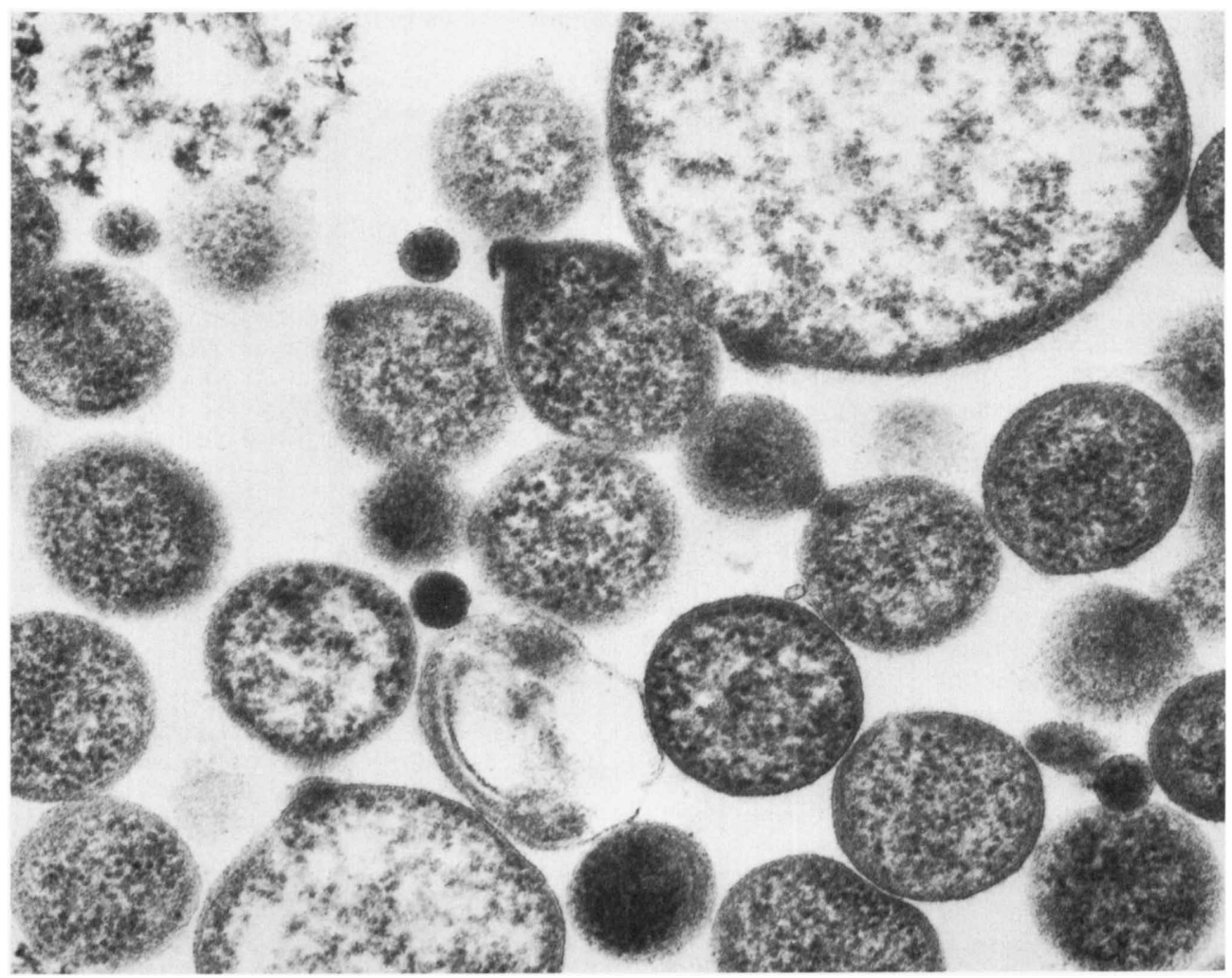

FIG. 2. Electron micrograph of strain $M K 405$ showing some budding. Final magnification, $\times 82,500$.

TABLE 3. Metabolic-inhibition titers with primate Mycoplasma and Acholeplasma species

\begin{tabular}{|c|c|c|c|c|c|c|c|c|}
\hline \multirow[b]{2}{*}{ Organism } & \multicolumn{8}{|c|}{ Reciprocal of MI titer ${ }^{a}$ for antisera to Mycoplasma and Acholeplasma } \\
\hline & $\begin{array}{c}M . \\
\text { hominis }\end{array}$ & $\begin{array}{c}M . \\
\text { fermentans }\end{array}$ & $\begin{array}{c}M . \\
\text { salivarium }\end{array}$ & $\begin{array}{c}M . \\
\text { orale I }\end{array}$ & $\begin{array}{c}M . \\
\text { orale II }\end{array}$ & $\begin{array}{c}M . \\
\text { primatum }\end{array}$ & $\begin{array}{c}\text { A. } \\
\text { laidlawii }\end{array}$ & $\begin{array}{c}M . \\
\text { moatsii }\end{array}$ \\
\hline $\begin{array}{l}\text { M. hominis } \\
M . \text { fermentans } \\
\text { M. salivarium } \\
\text { M. orale I } \\
\text { M. orale II } \\
\text { M. primatum } \\
\text { A. laidlawii } \\
\text { M. moatsii }\end{array}$ & 1,024 & 4,096 & 512 & 256 & 4,096 & 4,096 & 512 & 512 \\
\hline
\end{tabular}

${ }^{a}$ Based upon dilution of serum $(0.025 \mathrm{ml})$ which will inhibit 100 colony-forming units of the test Mycoplasma.

and were held in captivity for 21 days or less. They were received in two shipments, with four animals in one shipment and one in the second. At the time these samples were taken, none of the monkeys had gross signs of disease, although all were on preventive therapy. Since all isolates except one were recovered from the reproductive tract, it seems unlikely that they would be associated with respiratory disease or that the preventive treatment would have altered the existing flora. It is probable that this serotype falls into that large category of mycoplasmas which have not been associated with acute disease but which "turn up" in many tissues to plague investigators. It appears that this organism is indigenous to this animal. However, until the wild population itself and the human and animal populations of that 
TABLE 4. Metabolic-inhibition titers with species that utilize both glucose and arginine

\begin{tabular}{l|c|c}
\hline \multirow{2}{*}{ Antigen } & \multicolumn{2}{c}{ Reciprocal of MI titer ${ }^{a}$} \\
\cline { 2 - 3 } & $\frac{M \cdot \text { moatsii }}{\text { (MK 405) }}$ & $\frac{M . \text { fermentans }}{\text { (PG 18) }}$ \\
\hline $\begin{array}{l}\text { M. moatsii } \\
\begin{array}{l}\text { M. fermentans PG 18 } \\
\text { Sheep ATCC 23243 }\end{array}\end{array}$ & 512 & \\
\hline
\end{tabular}

${ }^{a}$ Titer based upon dilution of serum $(0.025 \mathrm{ml})$ which will inhibit 100 colony-forming units of the test Mycoplasma.

region have been studied, the ecology of this species cannot be definitely determined.

Thus, a new species of Mycoplasma consisting of six isolates was found to be serologically distinct from the known Mycoplasma species tested. On the basis of these findings, it is proposed that the new isolates be recognized as a new species, for which the name Mycoplasma moatsii is proposed (moat'si.i. M. L. gen.n. moatsii of Moats; named for K. E. Moats, whose primary interest has been in the mycoplasmas of nonhuman primates). The type strain is MK 405. It has been deposited in the American Type Culture Collection, Rockville, Md. under the number 27625.

\section{ACKNOWLEDGMENTS}

We thank M. L. Vernon for the electron microscopy work, H. Bloom and Dan Alger, Benton and Dickens Laboratory, Baltimore, Md., for agarose-gel diffusion plates, and Rebecca Gilbert for assistance in the preparation of this manuscript.

\section{REPRINT REQUESTS}

Address reprint requests to: Dr. David L. Madden, National Institute of Neurological Diseases and Stroke, Building 36, Room 5D04, Bethesda, Md. 20014.

\section{LITERATURE CITED}

1. Aluotto, B., R. G. Wittler, C. O. Williams, and J. E. Faber. 1970. Standardized bacteriologic technique for the characterization of Mycoplasma species. Int. J. Syst. Bacteriol. 20:35-38.

2. Chanock, R. M., L. Hayflick, and M. F. Barile. 1962. Growth on artificial medium of an agent associated with atypical pneumonia and its identification as a PPLO. Proc. Nat. Acad. Sci. U.S.A. 48:41-49.

3. Fox, H., R. H. Purcell, and R. M. Chanock. 1969. Characterization of a newly identified mycoplasma (Mycoplasma orale type 3 ) from the human oropharynx. J. Bacteriol. 98:36-43.

4. Hayflick, L. 1965. Tissue cultures and Mycoplasma. Tex. Rep. Biol. Med. 23(Suppl.):285-303.

5. Madden, D. L., R. J. Hildebrandt, G. R. G. Monif, W. T. London, N. B. McCullough, and J. L. Sever. 1970. The isolation and identification of Mycoplasma from Cercopithecus aethiops. Lab. Anim. Care 20:471-473.

6. Morton, H. E., and R. J. Roberts. 1967. The production of antimycoplasma (PPLO) antibodies in rabbits. Proc. Soc. Exp. Biol. Med. 125:538-543.

7. Purcell, R. H., D. Taylor-Robinson, D. C. Wong, and R. M. Chanock. 1966. A color test for the measurement of antibody to the non-acid-forming human Mycoplasma species. Amer. J. Epidemiol. $84: 51-66$.

8. Taylor-Robinson, D., R. H. Purcell, D. C. Wong, and R. M. Chanock. 1966. A color test for the measurement of antibody to certain Mycoplasma species based upon the inhibition of acid production. J. Hyg. 64:91-104. 